\title{
CD44 Is Exposed to the Extracellular Matrix at Invasive Sites in Basal Cell Carcinomas
}

\author{
Koert P. Dingemans, Marja D. Ramkema, and Steven T. Pals \\ Department of Pathology, Academic Medical Center, Amsterdam, The Netherlands
}

\begin{abstract}
SUMMARY: We have previously shown, by light microscopy, that the level of expression of CD44 (pan-CD44, CD44v3, CD44v5, and CD44v6) in human basal cell carcinomas is related to growth pattern and invasiveness ( $\mathrm{Br} \mathrm{J}$ Dermatol 1099;140:17-25). We have now studied the fine distribution of these CD44 isoforms in the same tumors using immunoelectron microscopy. Despite the strong differences in the level of expression in tumor areas with different growth patterns, CD44 was consistently found almost exclusively at intercellular surfaces, with a very strong predilection for widened intercellular pouches, ie, identical to the distribution in the normal epidermis. This prevalent distribution corroborates a role for CD44 in maintaining hyaluronan-filled spaces (J Histochem Cytochem 1998;46:241-248). However, the correlation between the presence of CD44 and the presence of such pouches was not absolute, indicating that other factors are involved as well. In contrast to the prevailing literature, we also found a weak but distinct labeling of cell surfaces facing the extracellular matrix. Interestingly, this appeared significantly elevated in the thinnest, most irregular, and usually most peripheral tumor cell strands, where it was associated with tumor cell protrusions and absence of a basal lamina. Thus, the $\mathrm{CD} 44^{+}$protrusions were in direct contact with the extracellular matrix and apparently represented sites of invasion. The mechanisms that may contribute to a role of CD44 at these sites include binding of extracellular matrix components (notably hyaluronan) and several biologically active factors such as hepatocyte growth factor/scatter factor and matrix metalloproteinase 9. (Lab Invest 2002, 82:313-322).
\end{abstract}

$C$ D44 is a family of cell surface glycoproteins consisting of standard CD44 (CD44s) and at least 30 alternative splice variants (CD44v), which are posttranslationally modified by $\mathrm{N}$ - and O-glycosylation and addition of glycosaminoglycan side chains (Bajorath, 2000). CD44 is involved in a large number of biologic processes, including lymphocyte homing and tumor invasion and metastasis. The involvement of CD44 in the latter processes is clearly evident from the finding that a specific CD44 splice variant conferred metastatic potential to a rat carcinoma cell line (Günthert et al, 1991) and from the close correlation between CD44 variant expression and the development of invasive human colorectal cancer (reviewed by Wielenga et al, 2000); but its precise role in these processes is far from elucidated. Possible mechanisms include the affinity of CD44 to a number of extracellular matrix components and its ability to anchor several biologically active factors (Nehls and Hayen, 2000; Wielenga et al, 2000).

One method to gather information on the role of CD44 in malignant invasion is to assess the distribution of CD44 expression in invasive tumors. We have previously analyzed, at the light microscopic level, the relation between CD44 expression and growth pattern of human basal cell carcinomas (BCC) (Dingemans et al, 1999). This tumor type is particularly interesting because of its huge spectrum of growth patterns

Received November 15, 2001.

Address reprint requests to: Dr. K. P. Dingemans, Department of Pathology, Academic Medical Center, Meibergreef9, 1105 AZ Amsterdam, The Netherlands.E-mail: k.p.dingemans@amc.uva.nl
(Heenan et al, 1996; Wade and Ackerman, 1978), ranging from nodular, apparently noninvasive, to spiky and apparently highly invasive (Dixon et al, 1989; Jacobs et al, 1982). Furthermore, these widely divergent growth patterns can very often be found side by side within individual BCC (Dingemans et al, 1999; Jones et al, 1998; Ramdial et al, 2000; Sexton et al, 1990). Thus, the rates of CD44 expression in different growth patterns can be compared in immediately adjacent fields; this avoids variations introduced by comparing different tumors from different patients.

The main findings of our previous investigation were as follows. Tumor strands of different sizes and shapes showed a significantly stronger CD44 expression than rounded tumor nodules. The highest expression was found in the thinnest, most peripheral tumor strands, including apparently isolated tumor cells and the thin, peripheral extremities of larger strands. In accordance with the literature, the label was confined to intercellular spaces, whereas all epithelium-stroma interfaces were negative. Only in the thinnest strands mentioned, was there an indication that some label was present at the tumor-stroma interface as well. However, this could not be assessed with certainty on the basis of light microscopy.

Several questions remained to be answered. Was the fine distribution of CD44 in the preexistent epidermis and in the different growth patterns within tumors similar, despite the pronounced differences in labeling intensity? Could the presence of CD44 at the tumorstroma interface in the thinnest tumor cell strands be confirmed? And, if so, which parts of the free tumor cell surface were bearing CD44, eg, was there a 
basement membrane present at these places? To address these questions, we used immunoelectron microscopy to investigate the same tumors as studied previously by light microscopy.

\section{Results}

\section{Ultrastructure of BCC}

The ultrastructure of the BCC grossly resembled that of the basal and spinous layers of the epidermis, the main difference being a much smaller number of cell extensions (microvillus-like extensions and cell "bridges" with desmosomes), yielding a far smoother cell surface (Heenan et al, 1996). Also the tumor-stroma interface was generally remarkably smooth (Figs. 1 and 2) (McNutt, 1976). In accordance with the literature (Dingemans et al, 1999; Hewitt et al, 1996; Lever and Schaumburg-Lever, 1990; McNutt, 1976; Van Cauwenberge et al, 1983), most tumor cell groups were surrounded by a basal lamina which, by light microscopy, seemed continuous. On electron microscopy $(E M)$, the large, compact tumor cell groups usually showed continuous basal laminae (Fig. 1) but occasionally also showed short denuded areas (Fig. 2) or small pseudopodia penetrating the basal lamina (Fig. 3) (Kirihara et al, 1992). Larger basal lamina discontinuities were present especially at the fine, tapering peripheral ends of large tumor cell groups, where the tumor cell surface had irregular protrusions (Fig. 4), at the thinnest, irregular tumor cell strands (Barsky et al, 1987; De Rosa et al, 1994; Kallioinen et al, 1984; Miller, 1991).
As shown in Figure 2, areas that were largely free of basal lamina often contained irregular traces of basal lamina material. The presence of such traces is apparently responsible for the erroneous light microscopic impression of an almost continuous basement membrane throughout the tumor (Van Cauwenberge et al, 1983). In sharp contrast to the well-organized connective tissue usually found near basal lamina-covered tumor areas (Fig. 1), the connective tissue adjacent to basal lamina-free areas was often poorly structured (Fig. 2), with empty-looking spaces, fibrous longspacing collagen of the dispersed type (Dingemans and Teeling, 1994), and other signs of degeneration (McNutt, 1976). Frequently, the only recognizable matrix components in direct contact with the tumor cells or their protrusions were bundles of fine filaments, presumably fibronectin (not shown).

\section{Expression and Distribution of CD44 Epitopes}

In accordance with our previous light microscopic findings (Dingemans et al, 1999), the CD44 distribution was identical for all antibodies used, both in the tumor and in the preexisting epidermis. The only exception was the positivity of nonepithelial cells exclusively for CD44s (Heider et al, 1993; Mackay et al, 1994). Furthermore, the distribution of the label was identical in material processed for EM in different ways, ie, fresh frozen, directly embedded in lowicryl resin gold (LRG), and embedded in LRG after retrieval from paraffin.

The intensity of the labeling, on the other hand, showed substantial differences, related to both the
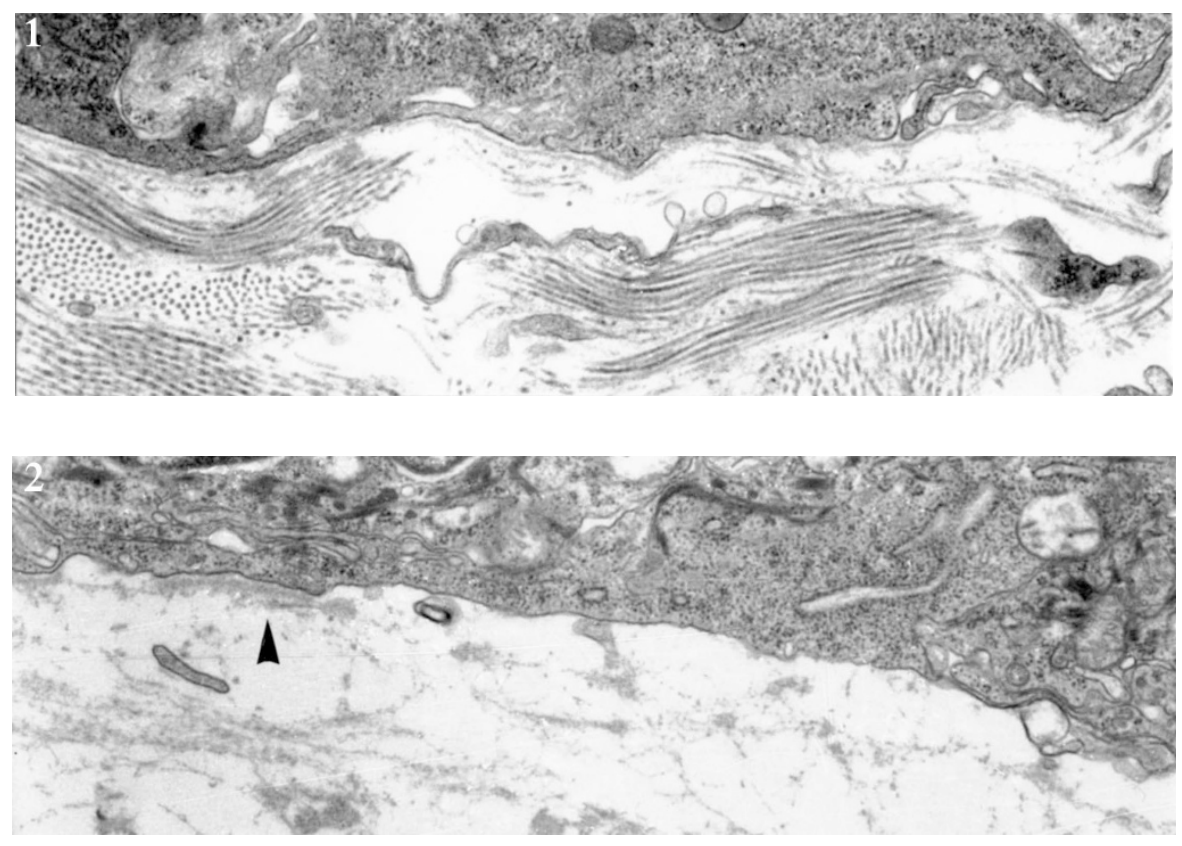

Figure 1.

Interface between large, compact tumor cell group and surrounding stroma. Tumor surface is relatively smooth and covered by continuous basal lamina. Stroma contains collagen fibers of normal aspect. $\times 21,500$.

Figure 2.

Denuded area of large, compact tumor cell group very near to previous figure. Only trace of basal lamina (arrowhead) is present. Adjacent stroma appears structureless and empty. Original magnification, $\times 21,500$. 


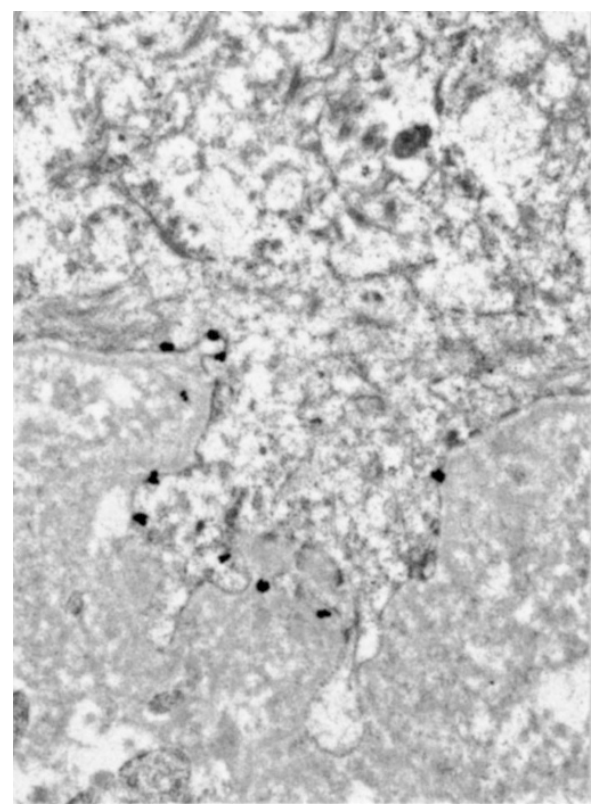

Figure 3.

Detail of large, compact tumor cell group showing tumor cell pseudopodium penetrating basal lamina. LRG, silver enhancement. Note presence of CD44 on tumor cell surface in pseudopodium but almost complete absence on basal lamina-covered surface. Original magnification, $\times 17,400$.

processing of the material and the antibody used. Freshly frozen material (Fig. 5) always showed a much stronger labeling than material directly embedded in LRG (Figs. 6 and 7), which was, in turn, labeled much stronger than material embedded in LRG only after retrieving it from paraffin (Fig. 8). In each of these specimen-processing methods, the highest labeling intensity was found with mAb Hermes 3 , which recognizes an epitope on the constant part of CD44. Most illustrations in the present article therefore show material stained with this mAb. Unless stated otherwise, material used for immunoelectron microscopy was labeled with the mAb Hermes 3, directed against CD44s, with 15-nm gold particles as markers.

About $30 \%$ of the gold particles were closely associated in pairs (or, occasionally, triads), lying at a distance of about 20 to $35 \mathrm{~nm}$ of each other. This was evident in the epidermis as well as in the tumors and in frozen as well as in embedded material (Figs. 4 to 8). It probably reflects the dimerization of CD44, which is thought to stimulate many of its functions (Lesley et al, 1993; Sleeman et al, 1996; Yu and Stamenkovic, 1999).

\section{CD44 Labeling of Epidermis}

No difference was detectable between the epidermides near the tumors studied and the epidermides from nontumorous patients. Virtually all label was associated with plasma membranes, the great majority being found at widened intercellular pouches, very little at areas of close cell contact, and virtually none on junctions (mainly desmosomes) (Figs. 5 to 8). The labeling intensity gradually decreased from the stratum basale to the stratum granulosum, grossly paral- leling the gradual disappearance of intercellular pouches. However, this correlation was not absolute: the labeling along wide pouches seemed highest in the stratum basale, whereas most pouches in the upper stratum spinosum and the stratum granulosum expressed hardly any label (Figs. 6 and 7). This was confirmed by a counting on two epidermides. The 179 gold particles that were found per $100 \mu \mathrm{m}$ of cell surface facing intercellular pouches in the stratum basale was taken as $100 \%$; the value in the stratum spinosum then appeared to be only $65 \%$, and in the stratum granulosum, this figure had dropped to $32 \%$. The stratum corneum hardly showed any gold particles at all $(<1 \%)$.

\section{CD44 Labeling of BCC}

The labeling of tumor tissue varied greatly between different tumor areas but usually was distinctly below that in the epidermis (Baum et al, 1996; Dingemans et al, 1999). However, despite this variation, the localization on the cell surface was identical in all samples and all different tumor growth patterns examined. Thus, here also, the label was found largely at sites facing intercellular pouches, very little at sites of close cell contact, and none at all at intercellular junctions (Fig. $8, b$ and $c)$.

The gross distribution of CD44 over the tumors was identical to that found by light microscopy (Dingemans et al, 1999): (1) The labeling intensity in the tiniest tumor cell strands was exceptionally high in comparison to all larger tumor cell groups; sometimes it approached that of the epidermis. (2) There was usually a gradient in labeling intensity: in superficial tumor cell groups or superficial parts of large tumor cell groups (Fig. 8b), the labeling was already considerably below that found in the stratum spinosum of the adjacent epidermis (Fig. 8a), but in the deepest areas, it had dropped to a very low intensity (Fig. 8c). As in the epidermis, this lower intensity did not simply reflect a decrease of wide intercellular pouches, because these were usually present throughout the tumor (Fig. 8, b and c). Quantification of CD44 expression was performed on a section containing the epidermis, the immediately subepidermal part of a large nodule, and parts of the same nodule located 400 to $1500 \mu \mathrm{m}$ below the epidermis. When the expression on the keratinocyte surface facing intercellular pouches in the stratum spinosum of the epidermis (172 gold particles per $100 \mu \mathrm{m}$ ) was taken as $100 \%$, the expression in the superficial and deeper parts of the tumor was $39 \%$ and $20 \%$, respectively.

\section{CD44 on Epithelial-Stromal Interfaces}

Although epithelial-stromal interfaces appeared CD44- at first sight, very small numbers of gold particles were found upon closer examination. Especially in the epidermis with its well-formed, complete basement membrane, such gold particles were often found to be situated in small pockets between the basal surface of the basal keratinocytes and the basal 

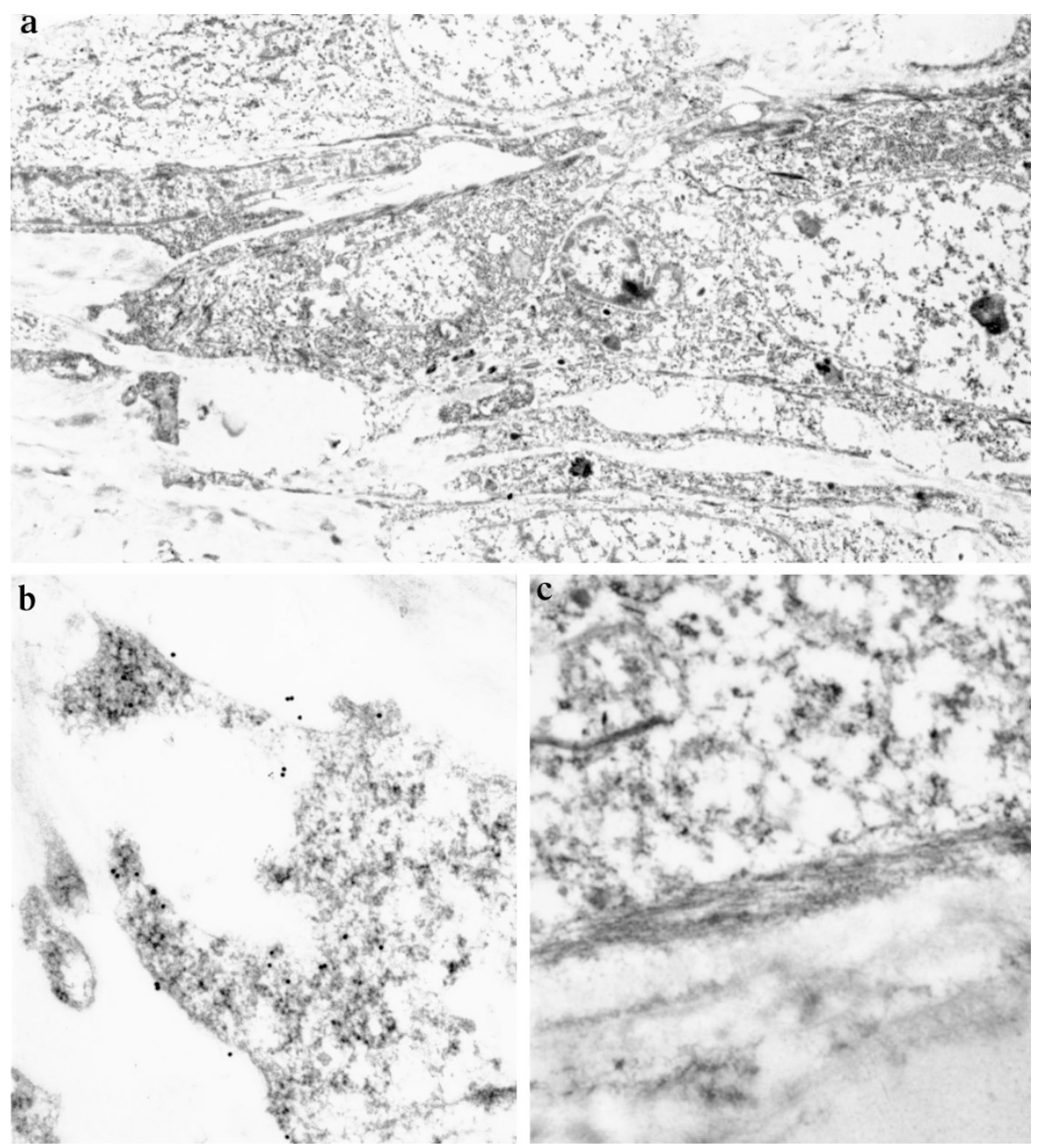

Figure 4.

a, Overview of tapering peripheral end of large tumor cell group. Paraffin-retrieved material. Original magnification, $\times 5200$.

b, Detail of "tip" of same tumor cell group as in a. Abundant label is located precisely at irregular protrusions. Surrounding stroma appears empty (compare with c). Original magnification, $\times 39.500$.

$\mathrm{c}$, Detail of tumor-stroma interface in same tumor cell group as in a and b, located about $40 \mu \mathrm{m}$ from tip. Tumor surface is smooth and CD44 negative. Prominent band of cytoplasmic filaments represents actin. In this paraffin-retrieved material, no basal lamina is unequivocally recognizable. However, in contrast to situation in $b$, the presence of extracellular matrix elements is evident. Original magnification, $\times 39,500$.

lamina (not shown). Apparently, at such sites the contact between a keratinocyte and the basal lamina was relatively loose. At the tumor-stroma interface, large tumor cell groups exhibited the same very weak labeling as found in the epidermis, whereas the thinnest, most peripheral tumor cell strands were distinctly positive. To confirm these observations, we performed a systematic quantitative analysis of the numbers of gold particles at the epithelial-stromal interfaces in those 15 paraffinretrieved $\mathrm{BCC}$ in which the preexistent epidermis and one or more distinct tumor areas were present in the same ultrathin section (see "Materials and Methods"). Next to the epidermis, the thin sections of these tumors contained 14 areas with large, compact tumor cell groups (either rounded nodules or strands) and 6 areas with very thin tumor strands or apparently isolated tumor cells. The results of the analysis (Table 1) show that the very low labeling intensity at the tumor-stroma interface in the large, compact tumor cell groups was very similar to that at the keratinocyte-stroma interface $(p=0.24)$.
On the other hand, the labeling intensity at the tumorstroma interface in the thinnest tumor strands was about 2.5 times higher than that at the keratinocyte-stroma interface; despite the small number of samples and the wide variation of values, this difference was statistically significant $(p=0.04)$.

Interestingly, at the tumor-stroma interface, the labeling was particularly high at the irregular, basement membrane-free parts of the tumor surface. As mentioned above, these were found especially at the thinnest peripheral strands of infiltrative areas, the very thin strands making up adenoid areas, the peripheral, tapering ends of large tumor cell groups (Fig. $4 \mathrm{~b})$, and at places were pseudopodia protruded into the surrounding stroma (Fig. 3).

\section{Proteoglycan Staining}

The distribution of proteoglycans, as observed after treatment of fresh tissue with polyethyleneimine, ap- 

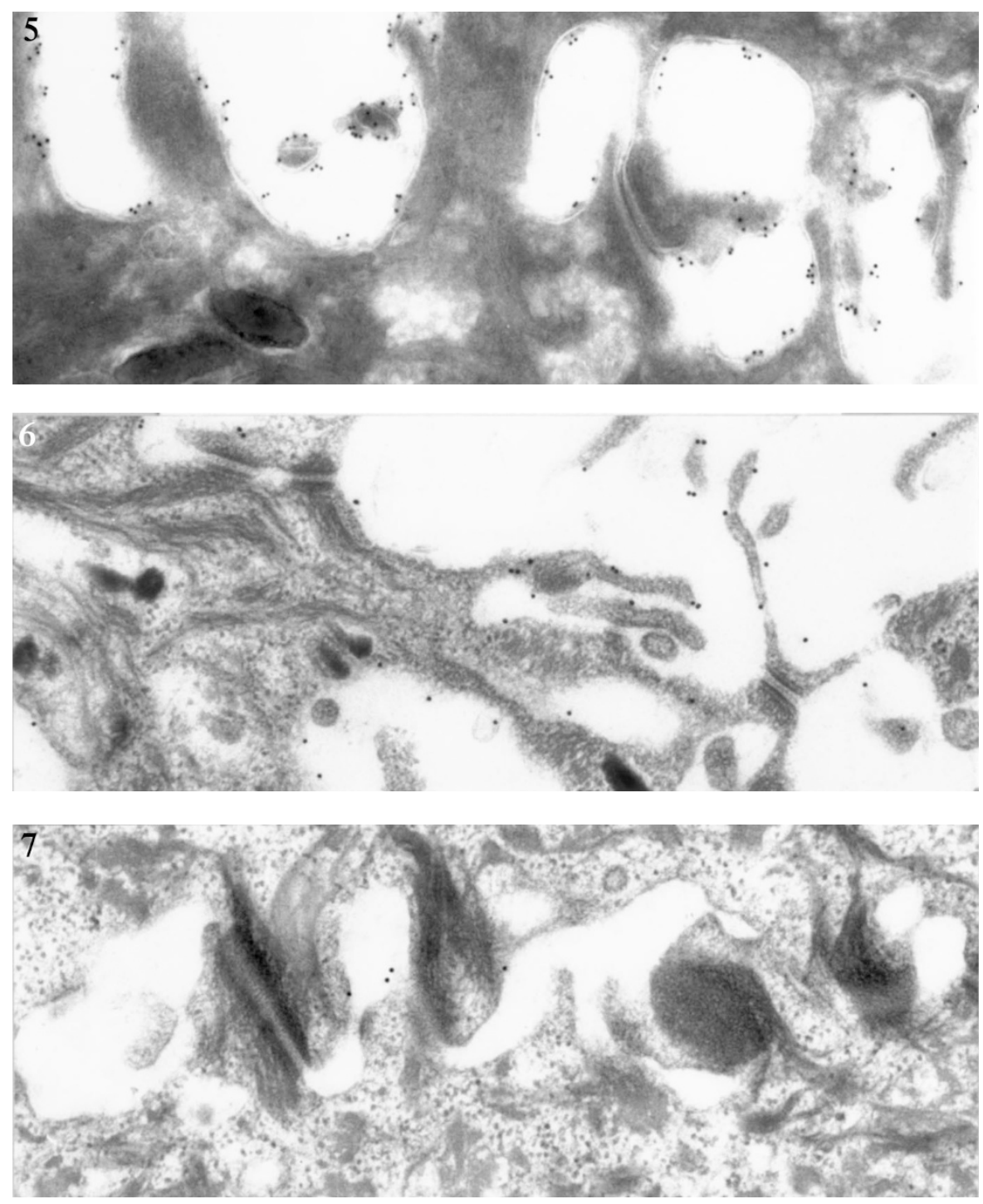

\section{Figure 5 .}

Epidermis, frozen section. Labeling, not with Hermes 3, directed against CD44s, as other illustrations, but with VFF6, directed against CD44v5. In stratum spinosum, numerous gold particles line keratinocyte surfaces facing intercellular pouches. Desmosome is negative. Original magnification, $\times 59,000$.

\section{Figure 6.}

Epidermis, LRG. Distribution of gold particles in stratum spinosum is identical to that in previous figure, but number is lower. Original magnification, $\times 59,000$.

\section{Figure 7.}

Epidermis, detail of transition zone between stratum spinosum and stratum granulosum, taken from same thin section as previous figure. Labeling of keratinocyte surface facing intercellular pouches is very weak in comparison to previous figure. Original magnification, $\times 59,000$.

peared identical to that of CD44, both in the epidermis and in the tumor tissue: (1) Wide intercellular pouches were abundantly labeled, whereas narrow intercellular slits were almost negative and junctions fully negative (Fig. 9a). (2) In the epidermis, the labeling gradually diminished in the direction of the stratum corneum, leaving the highest intercellular pouches in or near the stratum granulosum unlabeled (Fig. 9b). (3) Keratinocyte and tumor cell surfaces facing basal laminae were only very weakly labeled (although the basement membrane itself did carry abundant proteoglycan on either side). The proteoglycan particles appeared in markedly different sizes, apparently reflecting different classes of pro- teoglycans (Völker et al, 1987), but this was not further analyzed.

\section{Discussion}

Our study on the fine-structural distribution of CD44 in BCC was greatly helped by the use of archival paraffin-embedded material next to fresh tissue. Only paraffin-embedded material enables the controlled sampling on the basis of stained sections of whole tumors (Dingemans and Ramkema, 2001). However, the labeling intensity of CD44 in paraffin material is known to be low (Dietrich et al, 1997), and the ultrastructural preservation of paraffin- 


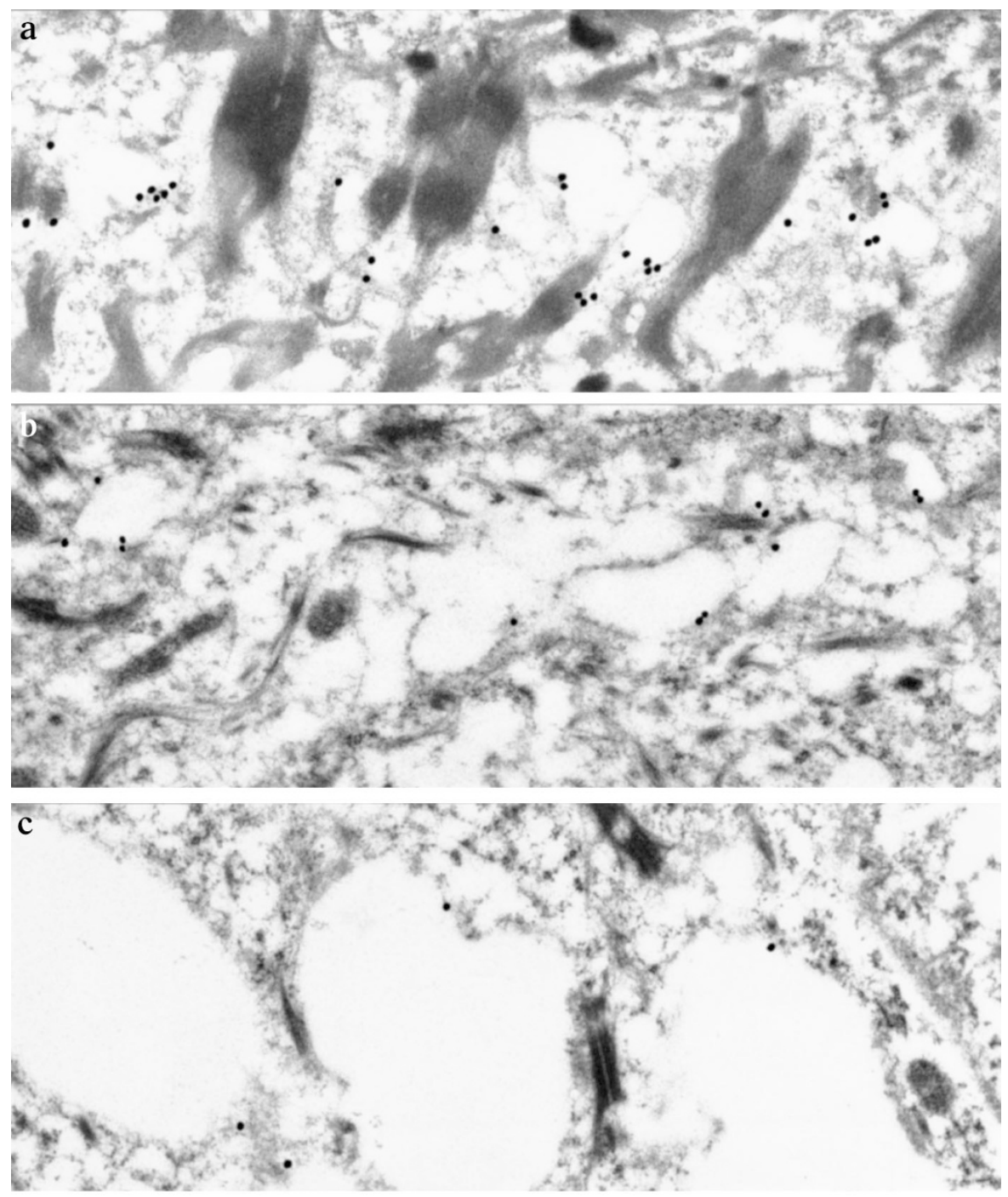

Figure 8.

Comparison of labeling in epidermis and in superficial and deep part of adjacent large, compact tumor nodule. Paraffin-retrieved material. For better visibility, gold particles have been manually accentuated in these overviews. Original magnification, $\times 24,000$.

a, Epidermis. Note conspicuous "cell bridges" with desmosomes and tonofibrils, and abundant labeling of cell surfaces facing wide intercellular pouches.

b, Superficial part of large tumor nodule, about $150 \mu \mathrm{m}$ from area shown in a. As in a, only cell surfaces facing intercellular pouches are labeled, but labeling intensity is considerably lower.

c, Part of same nodule as in b, but at depth of about $400 \mu \mathrm{m}$. Large intercellular pouches are present, but tumor cell surfaces facing them are only very weakly labeled.

Table 1. Quantitative Analysis of Gold Particles per $100 \mu \mathrm{m}$ of Keratinocyte-Stroma and Tumor-Stroma Interface

\begin{tabular}{lccccc}
\hline & $\begin{array}{c}\text { Samples } \\
\text { examined }\end{array}$ & $\begin{array}{c}\text { Total distance assessed } \\
(\mu \mathrm{m})\end{array}$ & Median & $\begin{array}{c}\text { Range } \\
\text { (lowest/highest) }\end{array}$ & Mean \\
\hline Keratinocyte-stroma interface & 15 & 1593 & 11.0 & $1-61$ & 16.88 \\
$\begin{array}{c}\text { Tumor-stroma interface (large, } \\
\text { compact tumor cell groups) }\end{array}$ & 14 & 721 & $9.5^{a}$ & $0-98$ & 13.07 \\
$\begin{array}{c}\text { Tumor-stroma interface (thinnest } \\
\text { tumor cell strands) }\end{array}$ & 6 & 817 & $34.0^{b}$ & $8-94$ & 41.42 \\
\hline
\end{tabular}

${ }^{a}$ Difference from keratinocyte-stroma interface not statistically significant $(p=0.24)$.

${ }^{b}$ Difference from keratinocyte-stroma interface statistically significant $(p=0.04)$.

retrieved material is generally relatively poor. It was therefore a surprise to find that it was suitable for such a detailed analysis. The reliability of the results is strongly supported both by the identical results obtained using fresh-frozen, LRG-embedded, or paraffin-retrieved material (Dietrich et al, 1997; Hale et al, 1995) and by the faithful reproduction at the EM level of our previous light microscopic observations (Dingemans et al, 1999). The finding of identical staining patterns with 10 different antibodies, 

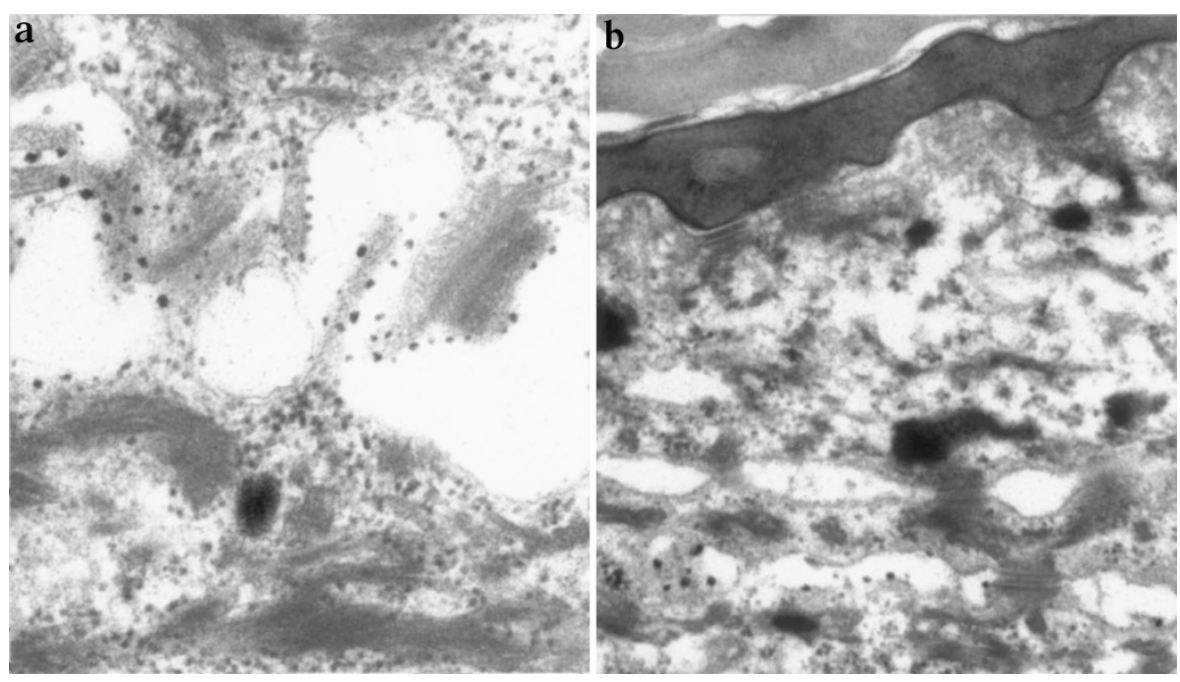

Figure 9.

Epidermis, treated with polyethylenimine to visualize proteoglycans.

a, Keratinocyte surfaces lining intercellular pouches in lower stratum spinosum are abundantly labeled with rounded electron-dense particles. Original magnification, $\times 53,500$.

b, Transition zone from stratum spinosum to stratum corneum, same thin section as a. Keratinocyte surfaces lining intercellular pouches in upper stratum spinosum (bottom) bear some label, but those located one cell layer higher, at the border of stratum spinosum and stratum granulosum, do not. Original magnification, $\times 41,500$.

directed against pan-CD44, CD44v3, CD44v5, and CD44v6, supports the notion that both epidermal keratinocytes and BCC cells predominantly synthesize CD44v3-10 (epican) (Haggerty et al, 1992; Kugelman et al, 1992).

The only detailed EM descriptions of the distribution of CD44 in the epidermis published previously are those by Tammi et al (1994) and especially Tuhkanen et al (1998). These authors found, just like we did, that CD44 was largely restricted to the cell surfaces facing intercellular pouches and the cell extensions protruding into them, with an almost complete exclusion of intercellular junctions. Kooy et al (1999) reported a preferential localization of CD44 at the site of intercellular junctions and other cell contacts, which is difficult to reconcile with our findings and those of Tuhkanen et al (1998). Also in accordance with Tuhkanen et al (1998), we found that the distribution of proteoglycans was identical to that of CD44 in every respect. This is not surprising, because the proteoglycan form of CD44 constitutes one of the major proteoglycans on keratinocytes (Tuhkanen et al, 1998; Zhou et al, 1999).

The first question prompting us to undertake the present study was whether the light microscopically observed differences in CD44 labeling intensity between the epidermis and the tumor tissue and between the various tumor growth patterns (Dingemans et al, 1999) were associated with differences in the fine distribution as well. As for the CD44 within the epithelial tissue compartments, this was not the case: all 22 epidermides and all 47 tumor areas available showed the same predilection of CD44 for cell surfaces facing wide intercellular pouches. This corroborates a role of CD44 in acting as a hyaluronan receptor and thereby in maintaining the wide intercellular spaces that are of decisive importance for the normal functioning of stratified epithelia (Tammi et al, 1988; Tuhkanen et al, 1998; Wang et al, 1992). Interestingly, we found that the correlation between the presence of widened intercellular pouches and the presence of CD44 (and of proteoglycans) was not absolute: in the higher levels of the epidermis and in most of the tumor tissue, many intercellular pouches were only weakly labeled and some were even fully negative. Apparently, at least part of the dilation of intercellular spaces was brought about by a mechanism independent from the hyaluronan-binding activity of CD44. Apart from the generally lower amount of label per unit distance of cell surface in tumors as compared with the epidermis, there was another factor obviously contributing to the relatively low light microscopically visible labeling of tumor tissue: most tumor cells had a far smaller number of extensions protruding into intercellular pouches than normal keratinocytes and, consequently, a far smaller total cell surface.

According to the literature, the epidermal-stromal interface is CD44 ${ }^{-}$or nearly CD44- (Haggerty et al, 1992; Hale et al, 1995; Kooy et al, 1999; Tuhkanen et al, 1998). No one therefore seems to have paid any attention to a possible significance of CD44 molecules that may be present at that site. In contrast, we consistently observed a small but distinct degree of labeling on the lower surface of the basal keratinocytes. The fact that we also found a statistically significantly higher label on the lower surface of the melanocytes (our unpublished data) strongly suggests that the presence of CD44 at the epidermal-dermal interface has functional implications, even if nothing presently is known about its nature.

The only difference between the CD44 distribution on the epidermis and on BCC was the presence of a distinctly increased amount of label along part of the 
tumor-stroma interface, especially that found at the smallest tumor cell strands. There was a strong correlation between the smoothness or irregularity of the tumor-stroma interface, the presence or absence of a basement membrane, and the intensity of CD44 labeling. Thus, almost all large tumor cell groups (that predominated in the centers of most tumors) had smooth contours, were lined by a basement membrane, and were only weakly CD $44^{+}$-apart from occasional places where small tumor cell protrusions penetrated the basement membrane and other small basement membrane discontinuities. On the other hand, the smallest tumor cell groups and the thinnest tumor cell strands (found especially in the tumor peripheries) often had very irregular contours and no, or only an incomplete, basement membrane and expressed a relatively large amount of CD44 on their outer surface, especially at cell protrusions.

The presence of CD44 precisely at apparent sites of invasion strongly suggests that CD44 plays a role in this process. Two of the possible mechanisms for this role are particularly exciting. Firstly, the binding of large amounts of hyaluronan by malignant tumor cells results in an expanded, hydrated peritumoral environment that is thought to facilitate tumor spread (Knudson, 1996; Toole et al, 1979). Secondly, CD44 (notably CD44v3) binds several biologically active factors, such as growth factors (Bennett et al, 1995) and matrix metalloproteinases. Of the growth factors bound by CD44, hepatocyte growth factor/scatter factor is probably the most interesting, because it has been implicated in tumor growth, invasion, and metastasis. The effects of hepatocyte growth factor/scatter factor on invasion involve cytoskeletal rearrangement leading to increased cell motility (Van der Voort et al, 2000). Furthermore, it has been demonstrated to control integrin activity, a process that is fundamental to the control of cell migration (Van der Voort et al, 1997). Yu and Stamenkovic (1999) have reported the binding by CD44 of the metalloproteinase MMP-9, which has the potential not only to degrade the basement membrane component collagen IV, but also to activate transforming growth factor- $\beta$ with its broad array of effects on invasion, growth stimulation, and angiogenesis (Yu and Stamenkovic, 2000).

\section{Materials and Methods}

\section{Collection and Classification of Tumor Material}

In our previous light microscopic study (Dingemans et al, 1999), a simple and straightforward classification of tumors and individual tumor areas into nodular, superficial, infiltrative, and adenoid growth patterns resulted in 53 separate tissue areas, present in a total of 27 tumors.

From each of these 27 tumors, at least one area exhibiting a characteristic growth pattern was retrieved from the original archival paraffin block and processed for immuno-EM. Despite a considerable decrease in preservation, the use of paraffin material offers the great advantage that tumor areas exhibiting specific growth patterns can be selected on the basis of existing stained sections. This method is far more reliable than using the tiny random tissue samples conventionally used for EM. Details about the method have been presented separately (Dingemans and Ramkema, 2001; Van den Bergh Weerman and Dingemans, 1984).

From seven BCC, fresh tissue was also available. Six freshly fixed skin samples from nontumorous patients served as additional controls. Fresh tissue samples were fixed in paraformaldehyde/glutaraldehyde $(2 \% / 0.1 \%)$ and embedded in LRG. In a number of cases, small samples fixed in the same fixative were used for cryosectioning.

Next to immuno-EM, conventional EM was performed in a few cases by fixing small pieces of fresh tissue in Karnovsky's fixative and embedding them in Epon. Thin sections were briefly pretreated with diluted tannic acid for better visualization of extracellular matrix components (Dingemans and Van den Bergh Weerman, 1990) before treating them with uranyl and lead according to standard procedures. In view of the close association of CD44 and proteoglycans, it was also of interest to study the distribution of proteoglycans that are hardly recognizable in conventional specimens. In a limited number of cases, proteoglycans were therefore visualized by treating freshly fixed tissue with polyethyleneimine 600 (Schurer et al, 1978).

\section{Immuno-EM}

Two-step labeling with protein A-gold was performed according to standard methods, usually with 15-nm gold particles as the label. Because these gold particles are invisible at low magnifications, silver enhancement was performed on a number of specimens to obtain an overview of the distribution of the label. This was done by applying ultrasmall gold particles (Aurion, Wageningen, The Netherlands) and expanding them using a silver enhancement kit (Aurion).

At the light microscopic level, an antigen retrieval procedure is indispensable for obtaining CD44 positivity on BCC (Dietrich et al, 1997). Also at the EM level, an antigen retrieval procedure (incubation of the sections in $0.01 \mathrm{M}$ citrate at $\mathrm{pH} 6,80^{\circ} \mathrm{C}$ for 10 minutes) did increase the labeling intensity. However, in view of the frequent breaking of supporting membranes during this procedure, we usually omitted it.

The following antibodies were used-two mAbs directed against pan-CD44: Hermes 3 (a gift of Dr. S. Jalkanen, Turku, Finland) and NKI-P1 (a gift of Dr. C. Figdor, Nijmegen, The Netherlands); an mAb directed against CD44v3: BBA11 (R\&D Systems, Abingdon, United Kingdom); four mAbs directed against CD44v5: BBA25 (R\&D), VFF6, and VFF8 (Bender, Vienna, Austria), and a mAb from Zymed (San Francisco, California); three mAbs directed against CD44v6: BBA13 (R\&D), VFF4 (Bender), and VFF18 (Bender).

Irrelevant IgG1, IgG2a, and IgG2b mAbs (Dako, Glostrup, Denmark) served as isotype-matched con- 
trols. Treatment with these antibodies consistently gave negative results.

\section{Quantitative Assessment of Labeling Intensity at the Epithelial-Stromal Interface}

In view of its superior possibilities for sampling areas with defined growth patterns, outlined above, paraffinretrieved material was used for the quantitative assessment of the presence of CD44 at epithelialstromal interfaces in different tumor areas. To increase the reliability of the comparison between tumor and preexistent epidermis, we included only the 15 BCC in which the epidermis was present in the same thin section as internal control.

Of each tissue area, 10 consecutive electron micrographs containing the epithelial-stromal interface were made at a magnification of $\times 2,600$, ie, a magnification at which gold particles are invisible in the EM and therefore cannot bias the observer. The negatives were printed at a final magnification of $\times 15,600$; gold particles along the epithelial-stromal interface were then identified and counted with a binocular viewer, and the length of the epithelial-stromal interface was established with the aid of a QUin system (Leica, Cambridge, United Kingdom). The nonparametric Mann-Whitney $U$ test was used to compare the labeling index (gold particles per $100 \mu \mathrm{m}$ of epithelialstromal interface) of normal epidermis, large compact tumor cell groups, and the thinnest tumor cell strands. All $p$ values were two-sided; a $p$ value $<0.05$ was considered statistically significant.

\section{Acknowledgement}

We are grateful to Dr. Josbert Keller for help in the statistical analysis.

\section{References}

Bajorath J (2000). Molecular organization, structural features, and ligand binding characteristics of CD44, a highly variable cell surface glycoprotein with multiple functions. Prot Struct Funct Genet 39:103-111.

Barsky SH, Grossman DA, and Bhuta S (1987). Desmoplastic basal cell carcinomas possess unique basement membranedegrading properties. J Invest Dermatol 88:324-329.

Baum HP, Schmid T, Shock G, and Reichrath J (1996). Expression of CD44 isoforms in basal cell carcinomas. $\mathrm{Br} \mathrm{J}$ Dermatol 134:465-468.

Bennett KL, Modrell B, Greenfield B, Bartolazzi A, Stamenkovic I, Peach R, Jackson DG, Spring F, and Aruffo A (1995). Regulation of CD44 binding to hyaluronan by glycosylation of variably spliced exons. J Cell Biol 131:1623-1633.

De Rosa G, Barra E, Guarino M, Staibano S, Donofrio V, and Boscaino A (1994). Fibronectin, laminin, type IV collagen distribution, and myofibroblastic stroma reaction in aggressive and nonaggressive basal cell carcinoma. Am J Dermatopathol 16:258-267.

Dingemans KP and Ramkema M (2001). Immunoelectron microscopy on material retrieved from paraffin: Accurate sampling on the basis of stained paraffin sections. Utrastruct Pathol 25:201-206.
Dingemans KP, Ramkema M, Koopman G, Van der Wal AC, Das PK, and Pals ST (1999). The expression of CD44 glycoprotein adhesion molecules in basal cell carcinomas is related to growth pattern and invasiveness. $\mathrm{Br} \mathrm{J}$ Dermatol $140: 17-25$.

Dingemans KP and Teeling P (1994). Long-spacing collagen and proteoglycans in pathological tissues. Ultrastruct Pathol 18:539-547.

Dingemans KP and Van den Bergh Weerman MA (1990). Rapid contrasting of extracellular elements in thin sections. Ultrastruct Pathol 14:519-527.

Dietrich A, Tanczos E, Vanscheidt W, Schöpf E, and Simon JC (1997). Detection of CD44 splice variants in formalinfixed, paraffin-embedded specimens of human skin cancer. J Cutan Pathol 24:37-42.

Dixon AY, Lee SH, and McGregor DH (1989). Factors predictive of recurrence of basal cell carcinoma. Am J Dermatopathol 11:222-232.

Günthert U, Hofmann M, Rudy W, Reber S, Zöller M, Haussmann I, Matzku S, Wenzel A, Ponta H, and Herrlich P (1991). A new variant of glycoprotein CD44 confers metastatic potential to rat carcinoma cells. Cell 65:13-24.

Haggerty JG, Bretton RH, and Milstone LM (1992). Identification and characterization of a cell surface proteoglycan on keratinocytes. J Invest Dermatol 99:374-380.

Hale LP, Patel DD, Clark RE, and Haynes BF (1995). Distribution of CD44 variant isoforms in human skin: Differential expression in components of benign and malignant epithelia. J Cutan Pathol 22:536-545.

Heenan PJ, Elder DE, and Sobin LH (1996). Histological typing of skin tumours. Berlin: Springer.

Heider KH, Hofmann M, Horst E, Van den Berg F, Ponta H, Herrlich P, and Pals ST (1993). A human homologue of the rat metastasis-associated variant of CD44 is expressed in colorectal carcinomas and adenomatous polyps. J Cell Biol 120:227-233.

Hewitt RE, Linton V, Powe DG, Sam W, Stevens A, and Turner DR (1996). Morphometric evidence that epithelial basement membrane breaks are a feature of both squamous and basal cell carcinomas of the skin. Int J Cancer 66:24-28.

Jacobs GH, Rippey JJ, Altini M, and Dent M (1982). Prediction of aggressive behavior in basal cell carcinoma. Cancer 49:533-537.

Jones MS, Maloney ME, and Billingsley EM (1998). The heterogenous nature of in vivo basal cell carcinoma. Dermatol Surg 24:881-884.

Kallioinen M, Autio-Harmainen H, Dammer K, Risteli J, and Risteli $L$ (1984). Discontinuity of the basement membrane in fibrosing basocellular carcinomas and basosquamous carcinomas of the skin: An immunohistochemical study with human laminin and type IV collagen antibodies. J Invest Dermatol 82:248-251.

Kirihara Y, Haratake J, and Horie A (1992). Clinicopathological and immunohistochemical study of basal cell carcinoma with reference to the features of basement membrane. J Dermatol 19:161-169.

Knudson W (1996). Tumor-associated hyaluronan: Providing an extracellular matrix that facilitates invasion. Am J Pathol 148:1861-1869. 
Kooy AJW, Tank B, De Jong AAW, Vuzevski VD, Van der Kwast TH, and Van Joost T (1999). Expression of E-cadherin, $\alpha$ - \& $\beta$-catenin, and $\mathrm{CD}_{44 \mathrm{~V}_{6}}$ in normal epidermis and basal cell carcinoma. Hum Pathol 30:1328-1335.

Kugelman LC, Ganguly S, Haggerty JG, Weissman SM, and Milstone LM (1992). The core protein of epican, a heparan sulfate proteoglycan on keratinocytes, is an alternative form of CD44. J Invest Dermatol 99:381-385.

Lesley J, Hyman R, and Kincade PW (1993). CD44 and its interaction with the extracellular matrix. Adv Immunol 54: 271-335.

Lever WF and Schaumburg-Lever G (1990). Histopathology of the skin. Philadelphia: Lippincott.

Mackay CR, Terpe HJ, Stauder R, Marston WL, Stark H, and Günthert U (1994). Expression and modulation of CD44 isoforms in humans. J Cell Biol 124:71-82.

McNutt NS (1976). Ultrastructural comparison of the interface between epithelium and stroma in basal cell carcinoma and control human skin. Lab Invest 35:132-142.

Miller SJ (1991). Biology of basal cell carcinoma (Part I). J Am Acad Dermatol 24:1-13.

Nehls V and Hayen W (2000). Are hyaluronan receptors involved in three-dimensional cell migration? Histol Histopathol 15:629-636.

Ramdial PK, Masaree A, Reddy R, and Chetty R (2000). bcl-2 protein in aggressive and non-aggressive basal cell carcinomas. J Cutan Pathol 27:283-291.

Schurer JW, Kalicharan D, Hoedemaeker J, and Molenaar I (1978). The use of polyethyleneimine for demonstration of anionic sites in basement membranes and collagen fibrils. $\mathrm{J}$ Histochem Cytochem 26:688-689.

Sexton M, Jones DB, and Maloney ME (1990). Histologic pattern analysis of basal cell carcinoma. J Am Acad Dermatol 23:1118-1126.

Sleeman J, Rudy W, Hofmann M, Moll J, Herrlich P, and Ponta H (1996). Regulated clustering of variant CD44 proteins increases their hyaluronate binding capacity. J Cell Biol 135:1139-1150.

Tammi R, Paukkonen K, Wang C, Horsmanheimo M, and Tammi M (1994). Hyaluronan and CD44 in psoriatic skin: Intense staining of hyaluronan on dermal capillary loops and reduced expression of CD44 and hyaluronan in keratinocyteleukocyte interfaces. Arch Dermatol Res 286:21-29.

Tammi R, Ripellino JA, Margolis RU, and Tammi M (1988). Localization of epidermal hyaluronic acid using the hyaluronate binding region of cartilage proteoglycan as a specific probe. J Invest Dermatol 90:412-414.
Toole BP, Biswas C, and Gross J (1979). Hyaluronate and invasiveness of the rabbit V2 carcinoma. Proc Natl Acad Sci USA 76:6299-6303.

Tuhkanen AL, Tammi M, Pelttari A, Agren UM, and Tammi R (1998). Ultrastructural analysis of human epidermal CD44 reveals preferential distribution of plasma membrane domains facing the hyaluronan-rich matrix pouches. $J$ Histochem Cytochem 46:241-248.

Van Cauwenberge D, Pierard GE, Foidart JM, and Lapiere CML (1983). Immunohistochemical localization of laminin, type IV and type $\mathrm{V}$ collagen in basal cell carcinoma. $\mathrm{Br} \mathrm{J}$ Dermatol 108:163-170.

Van den Bergh Weerman MA and Dingemans KP (1984). Rapid deparaffinization for electron microscopy. Ultrastruct Pathol 7:55-57.

Van der Voort R, Taher TEl, Derksen PWB, Spaargaren M, Van der Neut R, and Pals ST (2000). The hepatocyte growth factor/Met pathway in development, tumorigenesis, and B-cell differentiation. Adv Cancer Res 79:39-90.

Van der Voort R, Taher TEI, Keehnen RMJ, Smit L, Groenink $M$, and Pals ST (1997). Paracrine regulation of germinal center B cell adhesion through the c-Met-hepatocyte growth factor/scatter factor pathway. J Exp Med 185:2121-2131.

Völker W, Schmidt A, and Budeke E (1987). Mapping of proteoglycans in human arterial tissue. Eur J Cell Biol 45:7279.

Wade TR and Ackerman AB (1978). The many faces of basal-cell carcinoma. J Dermatol Surg Oncol 4:23-28.

Wang C, Tammi M, and Tammi R (1992). Distribution of hyaluronan and its CD44 receptor in the epithelia of human skin appendages. Histochemistry 98:105-112.

Wielenga VJ, van der Neut R, Offerhaus GJ, and Pals ST (2000). CD44 glycoproteins in colorectal cancer: Expression, function, and prognostic value. Adv Cancer Res 77:169-187.

Yu Q and Stamenkovic I (1999). Localization of matrix metalloproteinase 9 to the cell surface provides a mechanism for CD44-mediated tumor invasion. Genes Devel 13:35-48.

Yu Q and Stamenkovic I (2000). Cell surface-localized matrix metalloproteinase-9 proteolytically activates TGF- $\beta$ and promotes tumor invasion and angiogenesis. Genes Devel 14: 163-176.

Zhou J, Haggerty JG, and Milstone LM (1999). Growth and differentiation regulate CD44 expression on human keratinocytes. In Vitro Cell Dev Biol Animal 35:228-235. 